\title{
Food and feeding habits of the Gangetic hairfin anchovy Setipinna phasa (Hamilton, 1822)
}

\author{
M. SERAJUDDIN AND BRIJESH K. CHAUBEY* \\ Department of Zoology, Lucknow University, Lucknow - 226 007, Uttar Pradesh, India \\ Department of Zoology, Kashi Naresh Govt. P. G. College, Gyanpur, SR-Bhadohi - 222 002, Uttar Pradesh, India \\ e-mail:lu.fisheries@gmail.com
}

\begin{abstract}
Dietary composition and feeding intensity in relation to season, size and maturity stages of the Gangetic hairfin anchovy Setipinna phasa (Hamilton, 1822) were investigated in the present study. Strong dentition, modified gill rakers, strongly built stomach and short intestine were some of the basic characteristics associated with the feeding habits of $S$. phasa. Relative length of gut (RLG) indices indicated the absence of any major shift from basically carnivorous orientation of the fish during its various life stages. Feeding intensity was relatively high in stage III (gonad ripening stage) and low in the stages IV and V (ripe and spent). Insects and crustaceans were the main food of adults while annelids and insects were eaten by juveniles. Adult individuals of river Ganga consumed more food during winter than summer and rainy seasons, while the food intake in adult specimens of Hooghly Estuary was greater during summer compared to winter and rainy seasons. Study of food and feeding habits of fishes provides base line information for facilitating fisheries management programmes and sustainable aquaculture.
\end{abstract}

Keywords: Feeding intensity, Food composition, Hairfin anchovy, Setipinna phasa

\section{Introduction}

The freshwater hairfin anchovy Setipinna phasa (Hamilton, 1822) locally known as 'patra' is an economically important teleost fish found in fresh and brackishwaters of India and other countries such as Bangladesh and Burma. Jones and Menon (1951) reported that the fish abounds in all the deltaic branches of Ganga river system. S. phasa is the major species in artisanal catches in the Hooghly Estuary and Ganga river system at Allahabad-Varanasi region during November-March. The fish sold in the market comes from the wild, where the resource is dwindling in abundance due to uncontrolled exploitation. Despite its abundance, palatability and consumer demand; no scientific culture of this fish has been carried out due to the paucity of information on biology of this fish. Several studies have been carried out on this species including Jones and Menon (1951) who reported on the life history, bionomics and fishery of the Gangetic anchovy while Jhingran (1961) studied the maturity and fecundity. Study of morphological variation discernible by multivariate analysis between the species of genus Setipinna was carried out by Gangan et al. (2016), anomalies in pectoral and pelvic fins of two species of Setipinna and report on ecotypes of $S$. phasa from Indian waters have been carried out by Gangan et al. (2018a; b). A recent report of Gangan et al. (2019) emphasised the multigene barcoding and phylogeny of selected Engraulidae species from different regions of India.
Food is the most essential and the main source of energy for the growth and survival in fishes (Mamun et al., 2004) which plays an important role in determining the population levels, rate of growth and condition (Begum et al., 2008). Food and feeding habits of fishes vary with time of the day, size of the fish and season of the year (Serajuddin and Ali, 2005) and their studies have manifold importance in fishery biology, farming and management programmes (Bhuiyan et al., 2006; Begum et al., 2008; Sarkar and Deepak, 2009). Appropriate information regarding food and feeding habits of fish is an important requirement for fish production under aquaculture (Mamun et al., 2004). Therefore, the present study was undertaken to identify the feeding habits and dietary composition of $S$. phasa to generate basic information for developing culture technologies and to facilitate its sustainable aquaculture.

\section{Materials and methods}

A total of 360 fishes (200 from river and 160 from estuary) of size ranging between $60-340 \mathrm{~mm}$ were collected randomly using cast and drag nets from the river Ganga at Sant Ravidas Nagar, Bhadohi District $\left(25^{\circ} 9^{\prime} 32^{\prime \prime} \mathrm{N} ; 82^{\circ} 14^{\prime} 82^{\prime \prime} \mathrm{E}\right)$ and Hooghly Estuary at Kolkata $\left(22^{\circ} 34^{\prime} \mathrm{N} ; 8^{\circ} 24^{\prime} \mathrm{E}\right)$ (Fig. 1). Sampling was carried out for 12 months (September 2015 to August 2016), comprising 20-30 fish in each month. Total length of each fish was measured to nearest $0.1 \mathrm{~mm}$ using fish measuring board and their weight were record on an electronic balance 
of $0.001 \mathrm{~g}$ sensitivity. The fish were sexed and divided into six length groups of $50 \mathrm{~mm}$ class interval. Gonad condition of individual fish was examined to determine the stage of maturity (Qasim and Qayyum, 1961). Relative length of gut (RLG) (alimentary canal length expressed as percentage of body length) and gastrosomatic index (GSI) (gut weight expressed as percentage of body weight) were computed to study the feeding habits and intensity of feeding respectively. For analysis of gut contents, frequency of occurrence, numerical counts and gravimetric methods were used as per Serajuddin and Ali (2005). Qualitative analysis (identification of prey items in the gut contents) formed the basis for all relative quantitative assessments. For this purpose, the prey items were identified and categorised according to their systematic status by using the keys given by Pennak (1953), Ward and Whipple (1959) and Needham and Needham (1962).

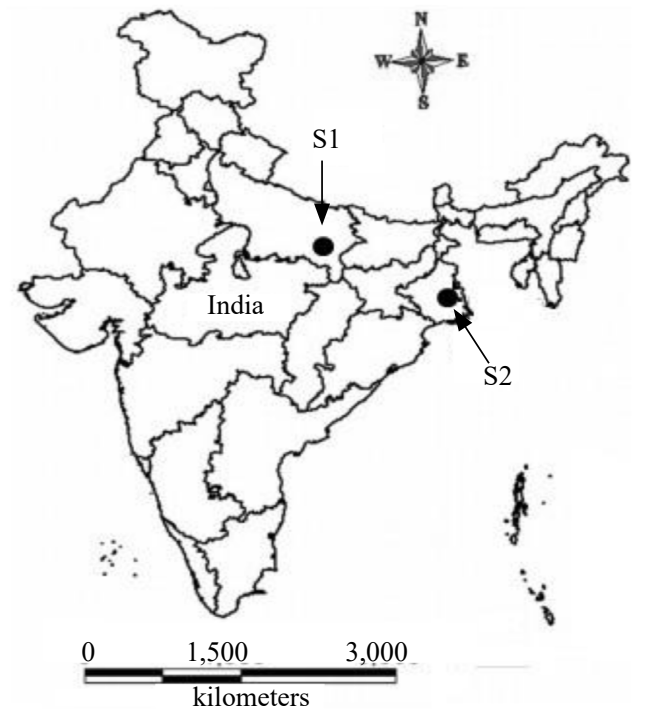

Fig. 1. Map of the sampling site. S1 = Ganga River at Sant Ravidas Nagar, Bhadohi District and S2 = Hooghly Estuary at Kolkata

\section{Results and discussion}

Morphology and anatomy of the organs concerned with feeding and digestion

The average percentage of body width with respect to the total body length was 17.62 and 20.47 in the fishes of river Ganga and Hooghly Estuary respectively, indicating a slender body suitable for its predatory habits. Laterally compressed body, well developed dentition, elongated thick walled stomach and short intestine together with the dominance of animal matter in the gut contents of $S$. phasa indicated its carnivorous and active predatory habits. Number of gill rakers varied between 22-24 which were widely spaced, elongated and spiny. Nature of gill rakers also supports the carnivorous nature of the fish. The gill raker is considered to be instrumental for capturing and sieving small prey items such as insects and crustaceans and also helpful in immobilising the prey. Das and Moitra (1956) and Marsh (1987) have opined that the gill rakers provide additional hold for gripping the prey in carnivorous fishes which help in feeding behaviour.

\section{Relative length of gut (RLG)}

The values of RLG for young and adult individuals of $S$. phasa are given in Table 1. Absence of any appreciable difference in this index $(0.39-0.59 \pm 0.020)$ in young and adult individuals indicated that the growth of $S$. phasa does not involve any major shift in their basically carnivorous orientation of the dietary habit. Similar observation was also reported by Serajuddin and Mustafa (1994) and Serajuddin and Ali (2005) in spiny eel, Mastacembelus armatus and in Macrognathus pancalus respectively. Serajuddin et al. (1998) correlated the relative length of gut with feeding habits of the fish, $M$. armatus and pointed out that the low values $(<1)$ for gut length/body length ratio hold up the carnivorous orientation of the fish. In view of the consistency in the gut length-body length ratio over the entire size range of the fish inclusive of both juveniles and adults, it was possible to express the relationship between gut length and body length as: log gut length $=-0.41292+1.41517 \mathrm{log}$ body length $(\mathrm{mm})$ (correlation coefficient $\mathrm{r}=0.945, \mathrm{p}<0.001$ ).

Table 1. Relative gut length of $S$. phasa in different length groups

\begin{tabular}{lll}
\hline Total length $(\mathrm{mm})$ & No. of observations & Relative gut index \\
\hline $60-100$ & 18 & $0.39 \pm 0.033$ \\
$110-150$ & 31 & $0.41 \pm 0.026$ \\
$160-200$ & 33 & $0.47 \pm 0.009$ \\
$210-250$ & 10 & $0.53 \pm 0.021$ \\
$260-300$ & 28 & $0.59 \pm 0.019$ \\
$310-350$ & 16 & $0.56 \pm 0.013$ \\
\hline
\end{tabular}

Feeding intensity in relation to season

Monthly values of GSI of $S$. phasa are given in Table 2. The adult individuals (both males and females) of S. phasa (160-220 mm) consumed more food during winter than summer and rainy seasons in River Ganga and during summer than rainy season and winter in the Hooghly Estuary. A pronounced feeding activity in the younger individuals of both sexes was observed in the month of September while it was extremely low in the month of December. In adult female specimens, a high value of GSI for all size ranges was recorded in the month of January, but in these cases the low values of GSI varied with size. The lowest values for the size group 260-300 and 310-350 mm was observed during the month of May and November respectively. The intensity of feeding declined 
during spawning season when the fish became ripe and was ready for spawning. Intrinsic factor in the form of stress brought to bear on the alimentary canal of the fish by the developed gonad appeared to be causative factor on the decline in its feeding intensity. The occurrence of poor feeding in other fishes coinciding with their peak breeding has also been reported by Jhingran (1961), Desai (1970), Serajuddin et al. (1998) and Faridi et al. (2016). The low feeding intensity in the month of November and during June - July may be due to the non-availability of food organisms in the environment and the effect of certain abiotic factors such as temperature and turbidity.

\section{Feeding intensity in relation to maturity stages}

Feeding intensity of male and female S. phasa at different stages of their maturation is given in Fig. 2 ( $a, b)$. Maximum value of feeding intensity was observed in the gonad ripening stage (stage III) which is the third stage of sexual cycle. This suggested that at this stage, the fish feeds more voraciously because of a higher demand for food for building up of the gonads (Serajuddin and Ali, 2005). Fish with medium gut fullness recorded in the present study in all months suggest that feeding was never discontinued. Khan et al. (1988) and Serajuddin et al. (1988) also reported the same type of feeding intensity in relation to the stage of maturity in Mystus nemurus and Mastacembelus armatus respectively.

\section{Food composition}

The foods from animal origin were most preferred by the fish compared to that of plant origin. Among the food of animal origin, insects dominated the diet of S. phasa throughout the year (Table 3). Other foods of animal origin were crustaceans (prawn), teleost fish

Table 2. Gastro-somatic index of S. phasa in different seasons

\begin{tabular}{|c|c|c|c|c|c|c|c|c|c|c|c|c|c|c|c|c|c|c|}
\hline \multirow{3}{*}{ Months } & \multicolumn{18}{|c|}{ Size range of fish (mm) } \\
\hline & \multicolumn{3}{|c|}{$60-100$} & \multicolumn{3}{|c|}{$110-150$} & \multicolumn{3}{|c|}{$160-200$} & \multicolumn{3}{|c|}{$210-250$} & \multicolumn{3}{|c|}{$260-300$} & \multicolumn{3}{|c|}{$310-350$} \\
\hline & $0^{n}$ & Q & $q^{1}$ & $0^{\prime \prime}$ & Q & $q^{7}$ & $0^{n}$ & Q & $q^{\pi}$ & $0^{n}$ & P & $\underline{\varphi}^{7}$ & $0^{n}$ & ○ & $\underline{q}^{x}$ & $0^{n}$ & ९ & 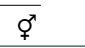 \\
\hline January & 2.3 & 1.8 & 2.1 & 3.1 & 3.5 & 3.2 & 4.3 & 3.2 & 3.5 & 3 & 3.8 & 3.2 & 3.1 & 3.4 & 3.2 & 2.1 & 3.7 & 3.2 \\
\hline February & 1.9 & 1.3 & 1.4 & 2.2 & 2.8 & 2.4 & 2.1 & 1.8 & 1.7 & 2.9 & 2.5 & 2.6 & 2.1 & 2.7 & 2.5 & 2.2 & 2.6 & 2.3 \\
\hline March & 1.3 & 1.8 & 1.6 & 2.1 & 1.9 & 2.0 & 3.2 & 2.1 & 2.2 & 2.5 & 1.8 & 1.9 & 3 & 2.6 & 2.4 & 3.1 & 2.7 & 2.9 \\
\hline April & 1.8 & 2.3 & 1.9 & 2.3 & 1.8 & 2.0 & 2.4 & 1.6 & 1.8 & 1.5 & 1.9 & 1.6 & 2.9 & 2.7 & 2.6 & 2.9 & 2.4 & 2.6 \\
\hline May & 1.4 & 1.8 & 1.5 & 1.9 & 2.3 & 2.1 & 1.9 & 1.6 & 1.7 & 2.6 & 3.1 & 3 & 1.6 & 1.8 & 1.6 & 2.2 & 1.9 & 2.0 \\
\hline June & 2.6 & 2.1 & 2.2 & 2.9 & 3.2 & 3.1 & 2.3 & 3.1 & 2.4 & 3.8 & 3.2 & 3.4 & 2.2 & 2.9 & 2.6 & 2.0 & 1.7 & 1.6 \\
\hline July & 2.3 & 1.1 & 1.8 & 3.0 & 3.6 & 3.2 & 2.5 & 2.9 & 2.6 & 3.1 & 2.8 & 2.9 & 2.4 & 2.7 & 2.2 & 1.9 & 1.8 & 1.6 \\
\hline August & 1.8 & 2.1 & 1.9 & 2.8 & 1.9 & 2.3 & 4.6 & 2.9 & 2.8 & 2.3 & 2.9 & 2.8 & 2.9 & 3.1 & 2.8 & 2.1 & 2.7 & 2.4 \\
\hline September & 3.2 & 1.8 & 2.4 & 2.2 & 2.9 & 2.4 & 3.9 & 2.6 & 3.2 & 3.2 & 1.9 & 2.5 & 1.9 & 2.6 & 2.5 & 2.3 & 1.9 & 2.0 \\
\hline October & 2.9 & 2.3 & 2.6 & 2.1 & 2.6 & 2.2 & 2.2 & 2.9 & 2.4 & 2.1 & 1.6 & 2.0 & 1.7 & 1.9 & 1.6 & 2.0 & 2.8 & 2.3 \\
\hline November & 2.5 & 1.8 & 2.1 & 1.6 & 1.9 & 1.7 & 2.3 & 1.9 & 2.1 & 2.2 & 1.8 & 1.9 & 2.1 & 2.8 & 2.3 & 1.9 & 1.6 & 1.5 \\
\hline December & 1.8 & 2.3 & 1.9 & 2.8 & 2.1 & 2.4 & 1.9 & 1.4 & 1.6 & 1.2 & 1.6 & 1.4 & 2.7 & 3.7 & 3.0 & 2.6 & 1.8 & 2.2 \\
\hline Mean & 2.1 & 1.8 & 1.9 & 2.4 & 2.5 & 2.4 & 2.6 & 2.3 & 2.3 & 2.5 & 2.3 & 2.4 & 2.3 & 2.7 & 2.4 & 2.2 & 2.3 & 2.2 \\
\hline $\mathrm{SE}( \pm)$ & \pm 0.16 & \pm 0.13 & \pm 0.14 & $0 \pm .21$ & \pm 0.19 & \pm 0.20 & \pm 0.29 & \pm 0.26 & \pm 0.27 & \pm 0.13 & \pm 0.09 & \pm 0.11 & \pm 0.26 & \pm 0.31 & \pm 0.28 & \pm 0.14 & \pm 0.16 & $6 \pm 0.15$ \\
\hline
\end{tabular}

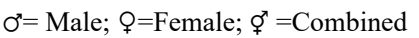

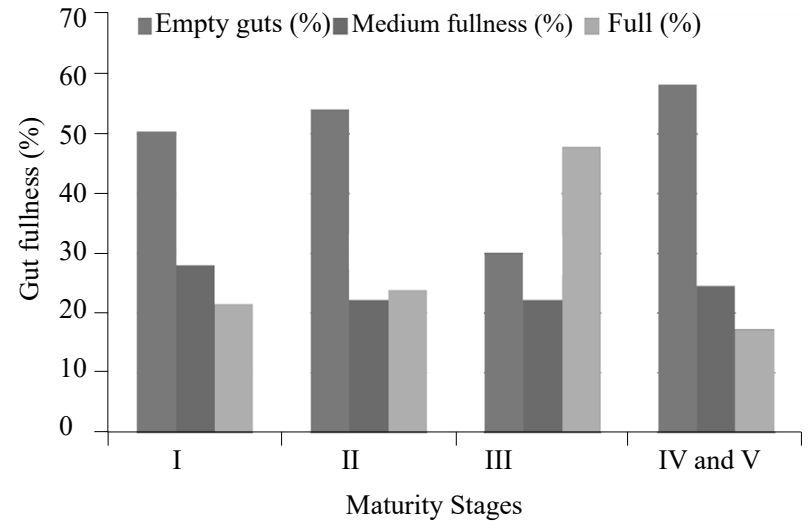

(a)

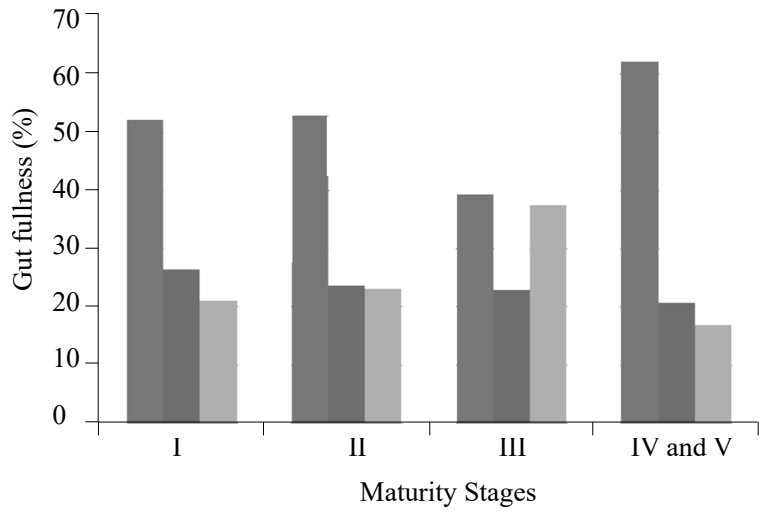

(b)

Fig. 2. Variation in the intensity of feeding with maturity stages of (a) male and (b) female S. phasa 
Table 3. Food items of S. phasa

\begin{tabular}{llll}
\hline Food items & Numerical count (\%) & Frequency of occurrence (\%) & Gravimetric index (\%) \\
\hline Animal origin & & & 89.53 \\
Insects & 72 & 34.821 & 08.60 \\
$\quad$ Chaoborus & 04 & 03.07 & 07.16 \\
Hemiptera & Numerous & 12.06 & 11.00 \\
$\quad$ Chironomid larvae & 09.16 & 05.60 \\
$\quad$ Unidentified aquatic insects & 34 & & 07.30 \\
Crustaceans & 29 & 24.03 & 22.63 \\
$\quad$ Prawn & 14 & 05.76 & 41.32 \\
$\quad$ Daphnia & 06 & 16.31 & 00.69 \\
Teleost fishes & 11 & 09.43 & 08.31 \\
$\quad$ Puntius spp. & 28 & 13.03 & 02.13 \\
$\quad$ Channa spp. & & 14.73 & 03.50 \\
$\quad$ Fish scale & 32 & & 07.36 \\
Annelids & & 04.36 & 46.31 \\
$\quad$ Earthworm & 12 & 04.90 & \\
Molluscs & 09 & 04.73 & \\
$\quad$ Gastropods & & 22.00 & \\
Barbles & - & & \\
Plant Origin & & & \\
$\quad$ Aquatic vegetation & - & & \\
Detritus & & & \\
$\quad$ Digested matter &
\end{tabular}

(Puntius spp.) and annelids (earthworm) in the order of frequency of occurrence in the gut. Molluscs and barbels were also recorded in the gut of the fish sporadically which might have been swallowed accidentally while feeding on other preferred items. Aquatic vegetation was found at irregular intervals. According to the criteria proposed by Nikolsky (1963), food organisms of $S$. phasa could be divided into categories viz., insects and crustaceans as basic food for adults and insects and annelids as basic food for juveniles (Fig. 3). However, annelids and forage fish could be regarded as secondary food for adults while forage fish and crustaceans together constituted the secondary food for juveniles. Molluscs and aquatic vegetation could be regarded as incidental items for both adults as well as juveniles.

The present study indicated that the fish, S. phasa is an active predator which prefers foods of animal origin and there was no major shift from basically carnivorous orientation of the fish during its various life stages. The intensity of feeding in relation to seasons varies with respect to the ecosystem. The riverine $S$. phasa feeds more voraciously during winter while estuarine fish feeds voraciously during summer. Fish with ripening stage of gonads consumes more food than fish during other maturity stages. The information generated from this study would be of use in developing programmes for breeding and farming of the species under captivity.

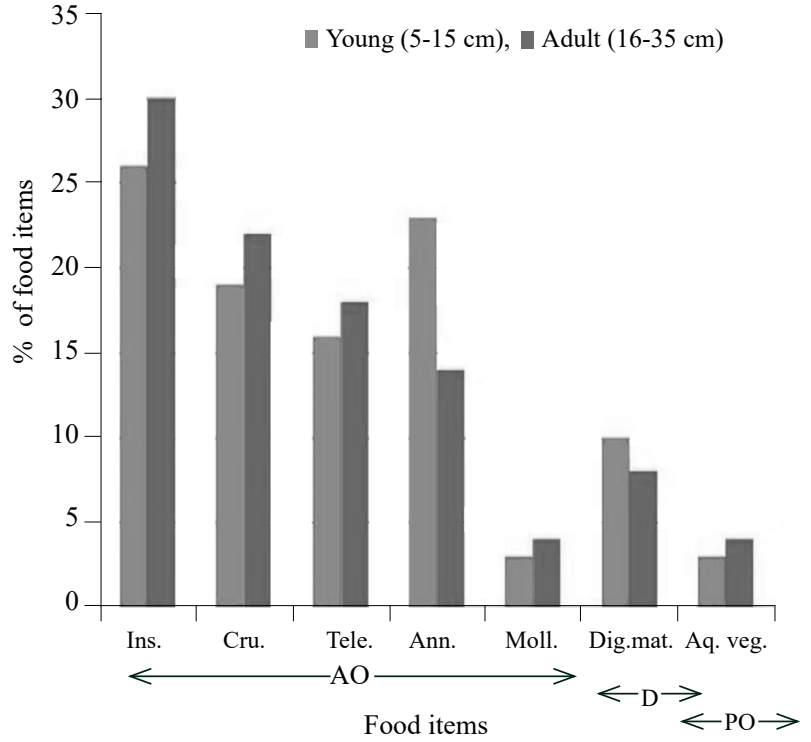

Fig. 3. Percentage composition of food of $S$. phasa $. \mathrm{AO}=$ Food of animal origin, $\mathrm{PO}=$ Food of plant origin and $\mathrm{D}=$ Detritus

\section{Acknowledgements}

The authors thank the Head, Department of Zoology, University of Lucknow for providing facility and administrative support.

\section{References}

Begum, M., Alam, M. J., Islam, M. A. and Pal, H. K. 2008. On the food and feeding habit of an estuarine catfish Mystus gulio 
(Hamilton) in the south-west coast of Bangladesh. University Journal of Zoology, Rajshahi University, 27: 91-94. doi:10.3329/ujzru.v27i0.1962.

Bhuiyan, A. S., Afroz, S. and Zaman, T. 2006. Food and feeding habit of the juvenile and adult snakehead, Channa punctatus (Bloch). J. Life Earth Sci., 1(2): 53-54.

Das, S. M. and Moitra, S. K. 1956. On the correlation between the fish food and fish gut in food fishes of U. P. $42^{\text {nd }}$ Proceedings of the Indian Science Congress, 4: 10.

Desai, V. R. 1970. Studies on the fishery and biology of Tor tor (Ham.) from river Narbada. J. Inland Fish. Soc. India, 2: $101-112$.

Faridi, A. A., Moshahid, M., Rizvi, A. and Serajuddin, M. 2016. Food and feeding habits of peacock eel, Macrognathus aculeatus (Bloch, 1786) from Eastern Uttar Pradesh, India. Int. J. Fish. Aquat. Stud., 4(4): 130-134.

Gangan, S. S., Kumar, R., Ramteke, K. K., Kumar, A. P. and Jaiswar, A. K. 2016. Study of morphological variation discernible by multivariate analysis between the species of genus Setipinna (Teleostei: Clupeiformes). Ecol. Env. Conserv., p. S11-S16.

Gangan, S. S., Jaiswar, A. K., Pavan-Kumar, A., Jahageerdar, S., Lakra, W. S. and Krishna, G. 2018a. A report on anomalies in pelvic fin and pectoral filament of two species of genus Setipinna (Swainson, 1839) from east coast of India. Ind. J. Geo. Mar. Sci., 1893-1898.

Gangan, S. S., Pavan-Kumar, A., Bamaniya, D., Jahageerdar, S., Lakra, W. S. and Jaiswar, A. K. A. 2018b. Report on ecotypes of Setipinna phasa (Hamilton-Buchanan, 1822) from Indian waters. Turk. J. Fish. Aquat. Sci., 18: 729-738.

Gangan, S. S., Pavan-Kumar, A. and Jaiswar, A. K. 2019. Multigene barcoding and phylogeny of selected Engraulidae species. Mito. DNA 30(3): 548-555. https:// doi.org/10.1080/24701394.2019.1570175.

Jhingran, A. G. 1961. Studies on the maturity and fecundity of Gangetic anchovy, Setipinna phasa (Ham.). Ind. J. Fish., 8: 291-311.

Jones, S. and Menon, P. M. G. 1951. Observations on the life history, bionomics and fishery of the Gangetic anchovy, Setipinna phasa (Ham.). J. Zool. Soc. India, 3: 323-333.
Khan, M. S., Ambak, M. A. and Mohsin, A. K. M. 1988. Food and feeding biology of a tropical catfish, Mystus nemurus with reference to its functional morphology. Indian J. Fish., 35: 78-84.

Mamun, A., Tareq, K. M. A. and Azadi, M. A. 2004. Food and feeding habits of Amblypharyngodon mola (Hamilton) from Kaptai Reservoir, Bangladesh. Pak. J. Biol. Sci., 7(4): 584-588. DOI: $10.3923 /$ pjbs.2004.584.588.

Marsh, P. C. 1987. Digestive tract contents of adult Razorbaceae suckers in lake Mohave, Arizona-Nevada. Trans. Am. Fish. Soc., 116: 117-119. https://doi.org/10.1577/15488659(1987).

Needham, J. G. and Needham, P. R. 1962. Guide to the study of freshwater biology, $5^{\text {th }}$ edn. Holden Day Inc., San Francisco, USA, 108 pp.

Nikolsky, G. V. 1963. The ecology of fishes. Academic Press, London, UK and New York, USA.

Pennak, R. W. 1953. Freshwater invertebrates of the United States. Ronald Press, New York, USA, 769 pp. https://doi. org/10.1163/156854077X00674.

Qasim, S. Z. and Qayyum, A. 1961. Spawning frequencies and breeding seasons of some freshwater fishes with special reference to those occurring in the plains of Northern India. Indian. J. Fish., 8: 24-43.

Sarkar, U. K. and Deepak, P. K. 2009. The diet of clown knife fish Chitala chitala (Hamilton-Buchanan) an endangered Notopterid from different wild population (India). Electronic J. Ichyol., 1: 11-20.

Serajuddin, M. and Mustafa, S. 1994. Feeding specialisations in adult spiny eel, Mastacembelus armatus. Asian Fish. Sci., 7: 63-65.

Serajuddin, M., Khan A. A. and Mustafa, S. 1998. Food and feeding habits of the spiny eel, Mastacembelus armatus. Asian Fish. Sci., 11: 271-278.

Serajuddin, M. and Ali, R. 2005. Food and feeding habits of striped spiny eel, Macrognathus pancalus (Hamilton). Indian J. Fish., 52(1): 81-86.

Ward, H. B. and Whipple, G. C. 1959. Freshwater biology. John Wiley and Sons, Inc., New York, USA, 124 pp. 